\title{
Cervical or Thoracic Anastomosis after Esophagectomy for Cancer: A Systematic Review and Meta-Analysis
}

\author{
S.S.A.Y. Biere K.W. Maas M.A. Cuesta D.L. van der Peet \\ Department of Surgery, VU University Medical Center, Amsterdam, The Netherlands
}

\section{Key Words}

Cervical anastomosis • Thoracic anastomosis •

Esophagectomy

\begin{abstract}
Background: Cervical anastomosis and thoracic anastomosis are used for gastric tube reconstruction after esophagectomy for cancer. This systematic review was conducted in order to identify randomized trials that compare cervical with thoracic anastomosis. Methods: A literature search for randomized trials was performed in the following databases: Medline, Embase and the Cochrane Library. Results: A total of 4 trials were included. All studies had a small sample size and were of moderate quality. One trial was excluded from the meta-analysis. The following outcomes were significantly associated with a cervical anastomosis: recurrent laryngeal nerve trauma (OR: 7.14; 95\% Cl: 1.75-29.14; $\mathrm{p}=0.006)$ and anastomotic leakage (OR: 3.43; 95\% Cl: 1.09-10.78; $p=0.03$ ). None of the following outcomes were associated with the location of the anastomosis: pulmonary complications (OR: $0.86 ; 95 \% \mathrm{Cl}: 0.13-5.59 ; \mathrm{p}=0.87)$, perioperative mortality (OR: 1.24; 95\% Cl: $0.35-4.41 ; \mathrm{p}=0.74)$, benign stricture formation (OR: $0.79 ; 95 \% \mathrm{Cl}: 0.17-3.87 ; \mathrm{p}=0.79$ ) or tumor recurrence (OR: 2.01; 95\% Cl: 0.68-5.91; $\mathrm{p}=0.21)$. Conclusion: Cervical anastomosis could be associated with a higher leak rate and recurrent nerve trauma. However, the currently available ran-
\end{abstract}

domized evidence is limited. Further randomized trials are needed to provide sufficient evidence for the preferred location of the anastomosis after esophagectomy.

Copyright $\odot 2011$ S. Karger AG, Basel

\section{Introduction}

In the 1940 s a $72 \%$ perioperative mortality was associated with esophagectomy for esophageal cancer [1]. In 1946, in order to reduce this mortality, Ivor Lewis [2] introduced a standardized approach to esophageal resection for carcinoma of the middle third of the esophagus. This approach involved a 2 -stage procedure that included a laparotomy, with a thoracotomy with thoracic anastomosis 1-2 weeks later. The risk of anastomotic leakage in the thorax with fatal consequences resulted in a 3-stage approach with a cervical anastomosis [3]. In case of leakage, a cervical fistula is a manageable complication [4]. However, an increased incidence of leakage and stricture formation could be associated with a cervical anastomosis.

Nowadays, both thoracic anastomosis and cervical anastomosis are used worldwide for gastric tube reconstruction after esophagectomy. Advocates of cervical anastomosis favor this location despite the possible increased incidence of leakage, benign stricture formation

S.S.A.Y. Biere, MD

Department of Surgery, VU University Medical Center

De Boelelaan 1117

NL-1081 HV Amsterdam (The Netherlands)

Tel. +31 204444 444, Fax +31 204444 512, E-Mail s.biere@vumc.nl 
and damage to the recurrent laryngeal nerve because of better tumor eradication as well as reduced mortality and morbidity associated with anastomotic breakdown. Several randomized controlled trials (RCTs) have been published in which cervical anastomosis are compared with thoracic anastomosis. To date, no systematic review or meta-analysis of the literature has been performed in order to identify the randomized trials performed in the past and to designate the appropriate anastomotic approach after esophagectomy. This systematic review was conducted in order to identify randomized trials that compare cervical with thoracic anastomosis after esophagectomy for carcinoma. A critical appraisal was performed and short- and long-term outcomes were assessed.

\section{Methods}

\section{Literature Search}

The following electronic databases were used for a literature search: Medline (1950 to March 2010), Embase (1947 to March 2010) and the Cochrane Library (2010 issue 1). A comprehensive search was performed using the following search terms: esophageal cancer, cervical, thoracic and anastomosis. Logical combinations of these and related terms (e.g. oesophagus, carcinoma, intrathoracic) were used to maximize sensitivity. Furthermore, a truncation symbol was used in each database in order to allow retrieval of all suffix variations of a root word (e.g. anastomos*).

A manual cross-reference search of the bibliographies of relevant articles was conducted to identify studies not found through the computerized search. The 'related articles' feature of PubMed was also used. Two reviewers executed the search independently (S.S.A.Y.B. and K.W.M.).

\section{Study Selection Criteria}

After identifying relevant titles, the abstracts of these studies were read to decide if the study was eligible. The full article was retrieved when the information in the title and/or abstract appeared to meet the objective of this review. All published randomized trials comparing cervical with thoracic anastomosis after esophagectomy for cancer were included. There were no restrictions with regard to the language of the published study.

\section{Quality Assessment of Retrieved Articles}

The 2 reviewers appraised each included article independently, assessing the methodological quality of the selected studies. A modified critical review checklist of the Dutch Cochrane Centre was used to appraise the RCTs (www.cochrane.nl; last accessed in November 2009). The following items of the checklist were negative for all surgical studies and were therefore not included for further appraisal (items: 1. Patient blinded? 2. Care provider blinded?).

\section{Data Extraction and Analysis}

Data was extracted on preformatted sheets. Two reviewers also performed this independently. The studies were tabulated and methodologically evaluated to assess homogeneity. In case of

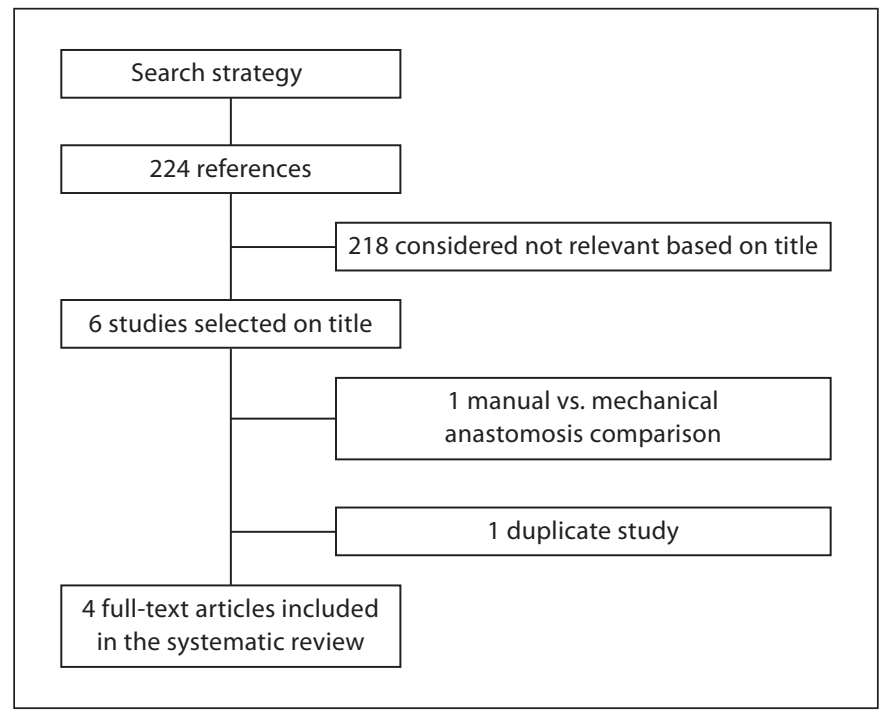

Fig. 1. Identification of eligible RCTs.

heterogeneity between studies, it was not justified to pool the assessed outcomes.

The following outcome parameters were assessed: pulmonary complications, anastomotic leakage, mortality, recurrent nerve trauma, positive resection margin (R1), length of hospital stay, stricture of anastomosis, tumor recurrence and predefined quality of life assessment.

\section{Statistical Analysis}

Meta-analyses were performed for outcome parameters when possible. Quantative data for the primary outcome parameters were entered into the software Cochrane Review Manager (RevMan) version 4.3 and analyzed using RevMan Analyses 1.0.5 (Cochrane Collaboration, Oxford, UK).

Summary estimates, including 95\% CI, were calculated. For continuous outcome data (e.g. length of hospital stay), means and $\mathrm{SD}$ were used to calculate a weighted mean difference in the metaanalysis. For dichotomous outcomes (e.g. mortality), the OR was calculated with the corresponding CI.

Statistical heterogeneity was tested using $\chi^{2}$ and $\mathrm{I}^{2}$ tests. Data were pooled using the random effect model as moderate heterogeneity was suspected (e.g. stapler devices).

\section{Results}

The initial search yielded 224 potential literature citations (fig. 1). Of these, 218 were excluded after scanning the title. Of the 6 studies considered potentially relevant, 2 were excluded. One study was excluded which compared manual anastomosis with mechanical anastomosis [5]. Another study was identified as a duplicate report in a non-English language journal [6]. A total of 4 random- 
Table 1. Characteristics of the included randomized trials

\begin{tabular}{|c|c|c|c|c|c|c|c|c|}
\hline \multirow[t]{2}{*}{ Study } & \multirow[t]{2}{*}{ Year } & \multirow[t]{2}{*}{ Journal } & \multirow{2}{*}{$\begin{array}{l}\text { Single center } \\
\text { or multicenter } \\
\text { trial }\end{array}$} & \multirow{2}{*}{$\begin{array}{l}\text { Surgical } \\
\text { approach }\end{array}$} & \multicolumn{2}{|c|}{ Type of anastomosis } & \multicolumn{2}{|c|}{ Number of patients included } \\
\hline & & & & & cervical & thoracic & $\begin{array}{l}\text { cervical } \\
\text { group }\end{array}$ & $\begin{array}{l}\text { thoracic } \\
\text { group }\end{array}$ \\
\hline Chasseray et al. [10] & 1989 & Surgery, Gynaecology and Obstetrics & single center & transthoracic & stapled $^{*}$ & stapled & 43 & 49 \\
\hline Ribet et al. [8] & 1992 & $\begin{array}{l}\text { Journal of Thoracic and } \\
\text { Cardiovascular Surgery }\end{array}$ & single center & transthoracic & hand-sewn & stapled & 30 & 30 \\
\hline Walther et al. [7] & 2003 & Annals of Surgery & single center & transthoracic & hand-sewn & stapled & 41 & 42 \\
\hline Okuyama et al. [9] & 2007 & Surgery Today & single center & transthoracic & hand-sewn & stapled & 18 & 14 \\
\hline
\end{tabular}

* 7 patients in the cervical group had a hand-sewn anastomosis.

Table 2. Methodological quality of the included randomized trials

\begin{tabular}{|c|c|c|c|c|c|c|c|}
\hline Study & $\begin{array}{l}\text { Excluded } \\
\text { patients }\end{array}$ & $\begin{array}{l}\text { Treatment alloca- } \\
\text { tion concealed? }\end{array}$ & $\begin{array}{l}\text { Eligibility crite- } \\
\text { ria specified? }\end{array}$ & $\begin{array}{l}\text { Groups similar } \\
\text { at baseline? }\end{array}$ & $\begin{array}{l}\text { Follow- } \\
\text { up? }\end{array}$ & $\begin{array}{l}\text { Intention } \\
\text { to treat? }\end{array}$ & $\begin{array}{l}\text { Similar nontrial } \\
\text { treatment? }\end{array}$ \\
\hline Chasseray et al. [10] & 31 & not stated & yes & yes & yes & yes & yes \\
\hline Ribet et al. [8] & 2 & yes & yes & yes & yes & no & yes \\
\hline Walther et al. [7] & 47 & yes & yes & yes & yes & yes & yes \\
\hline Okuyama et al. [9] & not stated & yes & yes & yes & yes & yes & yes \\
\hline
\end{tabular}

ized trials were included for the systematic review (table 1) [7-10]. These studies involved 267 patients, of which 132 patients were randomized for a cervical anastomosis and 135 patients had a thoracic anastomosis (table 1).

\section{Quality Assessment}

The quality assessment of the included studies is shown in table 2. Chasseray et al. [10] excluded 31 patients on account of a transhiatal approach being subsequently chosen for some patients, a nonresectable tumor or because the surgeon did not want to place the gastric tube in the posterior mediastinum. Furthermore, concealment of allocation was not reported in this study. In the cervical group, 8 patients had a retrosternal positioning of the gastric tube, and in 35 patients the gastric tube was placed in the posterior mediastinum. Importantly, only 7 of the 43 patients in the cervical anastomosis group had a hand-sewn anastomosis.

Ribet et al. [8] excluded 2 patients in the thoracic anastomosis group because a thoracic anastomosis could not be made. These patients were excluded from the analysis, with the result that no intention-to-treat analysis was performed.

Walther et al. [7] excluded 47 patients. Seventeen patients had a nonresectable tumor, of which 3 underwent a bypass procedure. Another 8 patients had a tumor located high in the esophagus, 8 patients had a jejunal or colon interposition, 6 patients refused participation, 4 had a palliative resection, 2 patients had a redo esophagectomy and 1 patient was operated on in another hospital. The results of the last 29 excluded patients were reported separately in this study. Patients with benign disease were also randomized and analyzed ( 2 patients in the cervical group and 7 patients in the thoracic group). Okuyama et al. [9] did not report the exclusion of patients. Eligibility was, however, described in this study.

Overall, the quality of the included studies was moderate. Chasseray et al. [10] only performed hand-sewn cervical anastomoses in 7 of the 43 patients; therefore, this study was excluded from the meta-analysis. The outcome parameters are depicted in table 3 . The meta-analyses are shown in table 4.

\section{Outcome Parameters}

Pulmonary Complications

The location of the anastomosis did not influence the incidence of pulmonary complications defined as pulmonary infection (OR: 0.86; 95\% CI: 0.13-5.59; $\mathrm{p}=0.87$ ). Chasseray et al. [10] reported a $16 \%(\mathrm{n}=7)$ incidence of respiratory complications in the cervical group. In the 
Table 3. Outcome parameters

\begin{tabular}{|c|c|c|c|c|c|c|c|c|}
\hline \multirow[t]{2}{*}{ Study } & \multicolumn{2}{|c|}{ Pulmonary complications } & \multicolumn{2}{|c|}{ Anastomotic leakage } & \multicolumn{2}{|c|}{ Mortality } & \multicolumn{2}{|c|}{ Positive resection margin } \\
\hline & $\begin{array}{l}\text { cervical } \\
\text { group }\end{array}$ & $\begin{array}{l}\text { thoracic } \\
\text { group }\end{array}$ & $\begin{array}{l}\text { cervical } \\
\text { group }\end{array}$ & $\begin{array}{l}\text { thoracic } \\
\text { group }\end{array}$ & $\begin{array}{l}\text { cervical } \\
\text { group }\end{array}$ & $\begin{array}{l}\text { thoracic } \\
\text { group }\end{array}$ & $\begin{array}{l}\text { cervical } \\
\text { group }\end{array}$ & $\begin{array}{l}\text { thoracic } \\
\text { group }\end{array}$ \\
\hline Chasseray et al. [10] & $7(16 \%)$ & $15(29 \%)$ & $11(26 \%)$ & $2(4 \%)$ & $4(9 \%)$ & $7(14 \%)$ & $1(2 \%)$ & $1(2 \%)$ \\
\hline Ribet et al. [8] & $21(70 \%)$ & $11(37 \%)$ & $9(30 \%)$ & $3(10 \%)$ & $5(17 \%)$ & $4(13 \%)$ & $3(10 \%)$ & $10(33 \%)$ \\
\hline Walther et al. [7] & $2(5 \%)$ & $4(10 \%)$ & $1(2 \%)$ & 0 & $1(2 \%)$ & $1(2 \%)$ & 0 & 0 \\
\hline Okuyama et al. [9] & $2(11 \%)$ & $5(36 \%)$ & $3(17 \%)$ & $1(7 \%)$ & 0 & 0 & not stated & not stated \\
\hline
\end{tabular}

${ }^{a}$ Reported in median. ${ }^{b}$ Reported in mean, no standard of mean was reported. ${ }^{c}$ Follow-up data only known for 29 patients.

Table 4. Meta-analysis of outcome parameters

\begin{tabular}{lll}
\hline & OR $(95 \% \mathrm{CI})$ & $\mathrm{p}$ \\
\hline Pulmonary complications & $0.86(0.13-5.59)$ & 0.87 \\
Anastomotic leakage & $3.43(1.09-10.78)$ & 0.03 \\
Mortality & $1.24(0.35-4.41)$ & 0.74 \\
Recurrent nerve trauma & $7.14(1.75-29.14)$ & 0.006 \\
Stricture of anastomosis & $0.79(0.17-3.87)$ & 0.79 \\
Tumor recurrence & $2.01(0.68-5.91)$ & 0.21 \\
\hline
\end{tabular}

thoracic anastomosis group, the incidence was 29\% ( $\mathrm{n}=$ 15). This difference in incidence did not reach statistical significance.

\section{Anastomotic Leakage}

A significant difference in incidence of anastomotic leakage is seen when comparing cervical anastomosis with thoracic anastomosis (OR: 3.43; 95\% CI: 1.09-10.78; $\mathrm{p}=0.03$ ). Chasseray et al. [10] reported significantly more anastomotic leaks in the cervical group (26 vs. $4 \%$; p < $0.02)$.

\section{Mortality}

The situation of the cervical anastomosis was not associated with a lower mortality (OR: 1.24; 95\% CI: 0.35-4.41; $\mathrm{p}=0.74$ ). Okuyama et al. [9] did not observe any perioperative mortality. Chasseray et al. [10] reported no significant difference in mortality between the cervical and thoracic anastomosis groups $[9 \%(\mathrm{n}=4)$ vs. $14 \%(\mathrm{n}=7)]$.

\section{Positive Resection Margin}

Only 2 of 3 RCTs eligible for the meta-analysis investigated the resection margins. One study did not observe any positive resection margin and the other study ob- served more positive margins in the thoracic group [10 $(n=3)$ vs. 33\% $(n=10)$ ]. Okuyama et al. [9] did not report the status of the resection margin. Chasseray et al. [10] reported 1 positive resection margin in each anastomotic group.

\section{Recurrent Nerve Trauma}

A cervical anastomosis was associated with significant more recurrent nerve trauma (OR: 7.14; 95\% CI: 1.7529.14; $\mathrm{p}=0.006$ ). Chasseray et al. [10] did not report on recurrent nerve trauma in their RCT.

\section{Hospital Stay}

Two of the 3 RCTs eligible for the meta-analysis reported length of hospital stay. Ribet et al. [8] calculated a mean hospital stay of 24.2 days for cervical anastomosis and 16.6 days for thoracic anastomosis. Walther et al. [7] calculated a median hospital stay which was not significantly different between the 2 groups (14 vs. 14 days).

\section{Benign Stricture of Anastomosis Requiring \\ Dilatation}

A cervical anastomosis was not associated with a significantly higher incidence of stricture of the anastomosis requiring dilatation (OR: 0.79 ; $95 \%$ CI: $0.17-3.87$; $\mathrm{p}=$ 0.79). Chasseray et al. [10] observed no significant difference between the cervical group compared with the thoracic group [23 $(\mathrm{n}=10)$ vs. $14 \%(\mathrm{n}=7)]$.

\section{Tumor Recurrence}

The location of the anastomosis did not significantly influence the incidence of tumor recurrence (OR: 2.01; 95\% CI: 0.68-5.91; $\mathrm{p}=0.21$ ). 


\begin{tabular}{|c|c|c|c|c|c|c|c|c|c|}
\hline \multicolumn{2}{|c|}{ Recurrent nerve trauma } & \multicolumn{2}{|c|}{ Hospital stay, days } & \multicolumn{2}{|c|}{ Stricture of anastomosis } & \multicolumn{2}{|c|}{ Tumor recurrence } & \multicolumn{2}{|c|}{ Quality of life assessment } \\
\hline $\begin{array}{l}\text { cervical } \\
\text { group }\end{array}$ & $\begin{array}{l}\text { thoracic } \\
\text { group }\end{array}$ & $\begin{array}{l}\text { cervical } \\
\text { group }\end{array}$ & $\begin{array}{l}\text { thoracic } \\
\text { group }\end{array}$ & $\begin{array}{l}\text { cervical } \\
\text { group }\end{array}$ & $\begin{array}{l}\text { thoracic } \\
\text { group }\end{array}$ & $\begin{array}{l}\text { cervical } \\
\text { group }\end{array}$ & $\begin{array}{l}\text { thoracic } \\
\text { group }\end{array}$ & $\begin{array}{l}\text { cervical } \\
\text { group }\end{array}$ & $\begin{array}{l}\text { thoracic } \\
\text { group }\end{array}$ \\
\hline not stated & not stated & $19.5(3-71)^{\mathrm{a}}$ & $18(2-122)^{\mathrm{a}}$ & $10(23 \%)$ & $7(14 \%)$ & 0 & 0 & not assessed & not assessed \\
\hline $6(20 \%)$ & $1(3 \%)$ & $24.2^{\mathrm{b}}$ & $16.6^{\mathrm{b}}$ & $4(13 \%)$ & $1(3 \%)$ & $9(60 \%)^{c}$ & $5(36 \%)^{c}$ & not assessed & not assessed \\
\hline $1(2 \%)$ & 0 & $14(6-68)^{\mathrm{a}}$ & $14(0-83)^{\mathrm{a}}$ & $8(20 \%)$ & $12(29 \%)$ & $1(2 \%)$ & $1(2 \%)$ & not assessed & not assessed \\
\hline $8(39 \%)$ & $1(7 \%)$ & not stated & not stated & 0 & $2(14 \%)$ & $4(22 \%)$ & $2(14 \%)$ & $\begin{array}{l}\text { no significant } \\
\text { difference }\end{array}$ & $\begin{array}{l}\text { no significant } \\
\text { difference }\end{array}$ \\
\hline
\end{tabular}

Quality of Life

Only Okuyama et al. [9] investigated the quality of life at 6 months after surgery. They assessed heartburn, regurgitation, stenotic sense, abdominal fullness, cough and wound pain. There was no significant difference between the cervical and thoracic anastomosis groups.

\section{Discussion}

This systematic review aimed to compare cervical anastomosis with thoracic anastomosis after esophageal resection for cancer. Four randomized trials were identified, of which 3 were eligible for the meta-analysis. The small sample sizes and moderate quality of the included studies brought limitations to the meta-analysis. A cervical anastomosis was associated with significantly more recurrent nerve trauma and anastomosis leakage. No significant differences were observed in pulmonary complications, perioperative mortality, benign strictures of the anastomosis requiring dilatation and tumor recurrence. There is insufficient data in this meta-analysis to report about the involvement of the resection margin, hospital stay and the quality of life after a cervical or thoracic anastomosis.

The traditional perception is that a thoracic anastomosis is associated with less frequent leaks; however, if they occur, they often have fatal consequences for the patient [11]. Although the CI of this meta-analysis almost reaches 1 , a significantly higher incidence of anastomotic leaks is seen when comparing cervical with thoracic anastomosis after esophagectomy. The location of the anastomosis could be a risk factor for leakage. However, cervical anastomoses could suffer more than thoracic anastomoses from ischemia of the gastric conduit $[12,13]$. Other possible factors that could contribute to leakage could be of a technical nature, related to gastric drainage or low institution and surgeon volume $[14,15]$. Walther et al. [7] performed a well-designed single center randomized trial analyzing both included patients and excluded patients. No significant difference in leak rate was identified between the groups. Furthermore, the higher leak rates for cervical anastomoses are generally more accepted because of the lower risk for the patient.

The significantly higher leak rate for cervical anastomosis did not result in a significantly higher mortality in the meta-analysis. Improved perioperative care could account for the absence of the direct relationship between anastomosis leakage and mortality in this analysis $[16,17]$. Okuyuma et al. [9] did not even observe any mortality in their trial. Worldwide, most surgical groups use a handsewn technique for cervical anastomosis and a mechanical technique for thoracic anastomosis. There does not seem to be a direct relationship with regard to the influence of the applied technique to outcome [18]. However, in order to minimize potential bias, only studies comparing hand-sewn cervical anastomosis with mechanical anastomosis were included in this systematic review.

A higher incidence of recurrent laryngeal nerve trauma is associated with cervical anastomosis in this metaanalysis. A narrow anatomical relationship exists between the recurrent nerve and the esophagus at the cervical level. Careful dissection and active identification of the recurrent nerve could minimize trauma to the nerve $[19,20]$. Furthermore, an underappreciation of recurrent nerve trauma exists in the literature, as not all patients with this trauma have symptoms of hoarseness, and interobserver variation exists in diagnosis [19]. None of the included trials indicated if a standard laryngoscopy or laryngoscopy on indication was performed postoperatively for recurrent nerve trauma. In the literature, recurrent nerve trauma is associated with pulmonary complications. This is thought to be caused mainly by aspiration 
$[19,21]$. In this meta-analysis, no significant difference in pulmonary complications was seen when comparing cervical anastomosis with thoracic anastomosis. Other factors could be of more influence in the incidence of pulmonary complications, e.g. adequate postoperative analgesics and physiotherapy.

Only 2 studies eligible for the meta-analysis reported on the involvement of the resection margin $[7,8]$. Walther et al. [7] did not observe any involvement of the resection margins in either the cervical or thoracic anastomosis groups. Ribet et al. [8] observed more positive resection margins in the thoracic group. Adequate preoperative and perioperative assessment probably accounts for the low incidence of involved resection margins $[22,23]$. These assessments also influence the tumor recurrence. No significant difference in tumor recurrence was seen in the meta-analysis. Therefore, it is probable that the involvement of the resection is comparable between the cervical and the thoracic anastomosis groups.

There are some reports that associate stricture formation with the use of stapler devices $[24,25]$. There is also evidence that anastomotic stricture is associated with anastomotic leakage $[25,26]$. Although there is a significantly higher incidence of anastomosis leakage with cervical anastomosis, benign stricture formation requiring dilatation is not associated with the location of the anastomosis in this meta-analysis. Other factors such as reflux could have more impact on stricture formation. The possible role of proton pump inhibitors in reducing reflux and therefore benign stricture formation has recently been investigated in a RCT [27]. A lower prevalence of benign stricture formation was observed in the group using proton pump inhibitors.

The present systematic review has several limitations. There were only 4 RCTs selected for inclusion. These included studies which were performed with a relatively small sample size. Only 3 trials were included for the me- ta-analysis as Chasseray et al. [10] used a stapled anastomosis in the cervical group. Two of these 3 trials were performed in the last 2 decades $[7,9]$. The other trial was conducted from 1983 to 1986 [8]. Changes in techniques and perioperative care could have influenced outcome. A bias due to change patterns of care, surgical techniques and improved suture devices could be present in this meta-analysis. RCTs from different time periods and continents could include some degree of heterogeneity in clinical approach. To address this issue, a random-effect model was used to meta-analyze the data. Furthermore, one should be aware that wide CI for some comparisons do not completely rule out the possibility of big increases, or big decreases, in risk. With regard to exclusion of patients, Chasseray et al. [10] excluded 31 patients for debatable reasons. Okuyama et al. [9] did not even report the exclusion of patients. A selection bias could be possible in these studies. Also, surgical and/or hospital factors are well known as having influence on the outcome. None of the included trials reported their yearly volume. Several of the aforementioned limitations of the trials have been recently addressed in the literature [28].

This systematic review shows that there are only 4 single center randomized trials available in the literature, and these have small sample sizes and are of moderate quality. In the meta-analysis of 3 trials, no difference in pulmonary complications, perioperative mortality, benign stricture formation or tumor recurrence after esophagectomy with a cervical or thoracic anastomosis for esophageal cancer was seen. A cervical anastomosis could, however, be associated with a higher incidence of recurrent laryngeal nerve trauma and anastomotic leakage. Further randomized trials in current clinical settings are needed to provide sufficient evidence for the preferred location of the anastomosis after esophagectomy for esophageal cancer. New anastomosis techniques could also be of interest for future randomized trials [29].

\section{References}

1 Oschner A, DeBakey M: Surgical aspects of carcinoma of the esophagus. J Thorac Surg 1941;10:401-445.

2 Lewis I: The surgical treatment of carcinoma of the oesophagus: with special reference to a new operation for growths of the middle third. Br J Surg 1946;34:18-31.

3 McKeown KC: Total three-stage oesophagectomy for cancer of the oesophagus. $\mathrm{Br} \mathrm{J}$ Surg 1976;63:259-262.

4 Scheepers JJ, van der Peet DL, Veenhof AA, Heijnen B, Cuesta MA: Systematic approach of postoperative gastric conduit complica- tions after esophageal resection. Dis Esophagus 2009;23:117-121.

5 Valverde A, Hay JM, Fingerhut A, Elhadad A: Manual versus mechanical esophagogastric anastomosis after resection for carcinoma: a controlled trial. French Associations for Surgical Research. Surgery 1996;120:476-483.

6 Ribet M, Debrueres B, Lecomte HM: Esophagectomy for advanced malpighian cancer of the thoracic esophagus. Esogastric anastomosis in the neck or in the thorax? Late results of a 'randomized' prospective study (in French). Ann Chir 1992;46:905-911. 
7 Walther BJ, Johansson J, Johnsson F, Von Holstein CS, Zilling T: Cervical or thoracic anastomosis after esophageal resection and gastric tube reconstruction: a prospective randomized trial comparing sutured neck anastomosis with stapled intrathoracic anastomosis. Ann Surg 2003;238:803-812.

8 Ribet M, Debrueres B, Lecomte HM: Resection for advanced cancer of the thoracic esophagus: cervical or thoracic anastomosis? Late results of a prospective randomized study. J Thorac Cardiovasc Surg 1992;103: 784-789.

9 Okuyama M, Motoyama S, Suzuki H, et al: Hand-sewn cervical anastomosis versus stapled intrathoracic anastomosis after esophagectomy for middle or lower thoracic esophageal cancer: a prospective randomized controlled study. Surg Today 2007;37:947-952.

10 Chasseray VM, Kiroff GK, Buard JL, et al: Cervical or thoracic anastomosis for esophagectomy for carcinoma. Surg Gynecol Obstet 1989;169:55-62.

11 Urschel JD: Esophagogastrostomy anastomotic leaks complicating esophagectomy: a review. Am J Surg 1995;169:634-640.

12 Holscher AH, Vallbohmer D, Brabender J: The prevention and management of perioperative complications. Best practice and research. Clin Gastroenterol 2006;20:907-923.

13 Reavis KM: The esophageal anastomosis: how improving blood supply affects leak rate. J Gastrointest Surg 2009;13:1558-1560.

14 Whooley BP, Law S, Alexandrou A, Murthy SC, Wong J: Critical appraisal of the significance of intrathoracic anastomotic leakage after esophagectomy for cancer. Am J Surg 2001;181:198-203.
15 Junemann-Ramirez M, Awan MY, Khan ZM, Rahamim JS: Anastomotic leakage post-esophagogastrectomy for esophageal carcinoma: retrospective analysis of predictive factors, management and influence on longterm survival in a high volume centre. Eur J Cardiothorac Surg 2005;27:3-7.

16 Iscimen R, Brown DR, Cassivi SD, Keegan MT: Intensive care unit utilization and outcome after esophagectomy. J Cardiothorac Vasc Anesth 2008;24:440-446.

17 Ruol A, Castoro C, Portale G, et al: Trends in management and prognosis for esophageal cancer surgery: twenty-five years of experience at a single institution. Arch Surg 2009; 144:247-254.

18 Urschel JD, Blewett CJ, Bennett WF, Miller JD, Young JE: Handsewn or stapled esophagogastric anastomoses after esophagectomy for cancer: meta-analysis of randomized controlled trials. Dis Esophagus 2001;14: 212-217.

19 Force S: The 'innocent bystander' complications following esophagectomy: atrial fibrillation, recurrent laryngeal nerve injury, chylothorax, and pulmonary complications. Sem Thorac Cardiovasc Surg 2004;16:117123.

20 Wright CD, Zeitels SM: Recurrent laryngeal nerve injuries after esophagectomy. Thorac Surg Clin 2006;16:23-33.

21 Gockel I, Kneist W, Keilmann A, Junginger $\mathrm{T}$ : Recurrent laryngeal nerve paralysis (RLNP) following esophagectomy for carcinoma. Eur J Surg Oncol 2005;31:277-281.

22 McManus K, Anikin V, McGuigan J: Total thoracic oesophagectomy for oesophageal carcinoma: has it been worth it? Eur J Cardiothorac Surg 1999;16:261-265.
23 Blewett CJ, Miller JD, Young JE, Bennett WF, Urschel JD: Anastomotic leaks after esophagectomy for esophageal cancer: a comparison of thoracic and cervical anastomoses. Ann Thorac Cardiovasc Surg 2001;7:75-78.

24 Rice TW: Anastomotic stricture complicating esophagectomy. Thorac Surg Clin 2006; 16:63-73.

25 Dresener SM, Lamb PJ, Wayman J, Hayes N, Griffin SM: Benign anastomotic stricture following transthoracic subtotal oesophagectomy and stapled oesophago-gastrostomy: risk factors and management. Br J Surg 2000;87:362-373.

26 Honkoop P, Siersema PD, Tilanus HW, Stassen LP, Hop WC, van Blankenstein M: Benign anastomotic strictures after transhiatal esophagectomy and cervical esophagogastrostomy: risk factors and management. J Thorac Cardiovasc Surg 1996;111:11411146.

27 Johansson J, Oberg S, Wenner J, Zilling T, Johnsson F, von Holstein CS, Walther B: Impact of proton pump inhibitors on benign anastomotic stricture formations after esophagectomy and gastric tube reconstruction: results from a randomized clinical trial. Ann Surg 2009;250:667-673.

28 Lagarde SM, Vrouenraets BC, Stassen LP, van Lanschot JJ: Evidence based surgical treatment of esophageal cancer: overview of high quality studies. Ann Thorac Surg 2010; 89:1319-1326.

29 Collard JM, Romagnoli R, Goncette L, Otte JB, Kestens PJ: Terminalized semimechanical side-to-side suture technique for cervical esophagogastrostomy. Ann Thorac Surg $1998 ; 65: 814-817$ 